16 Cnattingius S. Maternal age modifies the effect of maternal smoking on intrauterine growth retardation but not on late fetal death and placental abruption. Am J Epidemiol 1997;145:319-23.

17 Naeye RL. The duration of maternal cigarette smoking, fetal and placental disorders. Early Hum Dev 1979;3:229-37.

18 Raymond EG, Mills JL. Placental abruption. Maternal risk factors and associated fetal conditions. Acta Obstet Gynecol Scand 1993;72:633-9

19 Raymond EG, Cnattingius S, Kiely JL. Effects of maternal age, parity and smoking on the risk of stillbirth. Br J Obstet Gynaecol 1994;101:301-6.

20 Yudkin PL, Wood L, Redman CWG. Risk of unexplained stillbirth at different gestational ages. Lancet 1987;i:1192-4.

21 Cnattingius S, Larsson E, Weiner E. Uterine-arterial changes with age and smoking. Int J Feto-Maternal Med 1990;3:15-8.

22 Naeye RL. Maternal age, obstetric complications, and the outcome of pregnancy. Obstet Gynecol 1983;61:210-6.

23 Cnattingius S, Bergström R, Lipworth L, Kramer MS. Prepregnancy weight and the risk of adverse pregnancy outcomes. $N$ Engl J Med $1998 ; 338: 147-52$.

24 Little RE, Weinberg CR. Risk factors for antepartum and intrapartum stillbirth. Am J Epidemiol 1993;137:1177-89.

25 Rydhström H, Tydén T, Herbst A, Ljugblad U, Walles B. No relation between maternal weight gain and stillbirth. Acta Obstet Gynecol Scand 1994;73:779-81

26 Haglund B, Cnattingius S, Nordström M-L. Social differences in late fetal death and infant mortality in Sweden 1985-86. Pediatr Perinatal Epidemiol 1993:7:33-44.

27 Barros FC, Huttly SRA, Victora CG, Kirkwood BR, Vaughan JP. Comparison of the causes and consequences of prematurity and intrauterine growth retardation: a longitudinal study in southern Brazil. Pediatrics 1992;90:238-44

28 Lang JM, Lieberman E, Cohen A. A comparision of risk factors for preterm labor and term small-for-gestational-age birth. Epidemiolog 1996;7:369-76.

29 Alessandri LM, Stanley FJ, Garner JB, Newnham J, Walters BNJ. A case-control study of unexplained antepartum stillbirths. Br J Obstet Ginaecol 1992.99:711-8.

30 Rådestad I, Steineck G, Nordin C, Sjögren C. Psychological complications after stillbirth-influence of memories and immediate management: population based study. BMJ 1996;312:1505-8.

31 Genest DR, Williams MA, Greene MF. Estimating the time of death in stillborn fetuses: I. Histologic evaluation of fetal organs; an autopsy study of 150 stillborn. Obstet Gynecol 1992;80:575-84.

(Accepted 4 February 1998)

\title{
Cost effectiveness of community leg ulcer clinics: randomised controlled trial
}

\author{
C Jane Morrell, Stephen J Walters, Simon Dixon, Karen A Collins, Louise M L Brereton, Jean Peters, \\ Charles G D Brooker
}

\begin{abstract}
Objectives: To establish the relative cost effectiveness of community leg ulcer clinics that use four layer compression bandaging versus usual care provided by district nurses.

Design: Randomised controlled trial with 1 year of follow up.

Setting: Eight community based research clinics in four trusts in Trent.

Subjects: 233 patients with venous leg ulcers allocated at random to intervention (120) or control (113) group.

Interventions: Weekly treatment with four layer bandaging in a leg ulcer clinic (clinic group) or usual care at home by the district nursing service (control group).
\end{abstract}

Main outcome measures: Time to complete ulcer healing, patient health status, and recurrence of ulcers. Satisfaction with care, use of services, and personal costs were also monitored.

Results: The ulcers of patients in the clinic group tended to heal sooner than those in the control group over the whole 12 month follow up (log rank $\mathrm{P}=0.03)$. At 12 weeks, $34 \%$ of patients in the clinic group were healed compared with $24 \%$ in the control. The crude initial healing rate of ulcers in intervention compared with control patients was $1.45(95 \%$ confidence interval 1.04 to 2.03). No significant differences were found between the groups in health status. Mean total NHS costs were $£ 878.06$ per year for the clinic group and $£ 859.34$ for the control $(\mathrm{P}=0.89)$.

Conclusions: Community based leg ulcer clinics with trained nurses using four layer bandaging is more effective than traditional home based treatment. This benefit is achieved at a small additional cost and could be delivered at reduced cost if certain service configurations were used.

\section{Introduction}

Complete healing of venous leg ulcers can take years and recurrence is a problem. ${ }^{1}$ Patients experience pain, affecting sleep, mobility, and quality of life. ${ }^{2-4}$ The financial cost of venous disease in Britain has been estimated at between $£ 294 \mathrm{~m}$ and $£ 650 \mathrm{~m}$ a year. ${ }^{56}$ Most care for people with leg ulcers has been provided by community nurses, ${ }^{7}$ who use numerous treatments, although adequate information about their effect on complete healing or quality of life is not available. ${ }^{6}$

A unique graduated four layer compression bandaging system was pioneered at Charing Cross Hospital $^{9}$ and clinics in Riverside that used this system achieved a healing rate of $69 \%$ of venous ulcers in 12 weeks. ${ }^{10}$ Estimates indicated that costs for clinics were lower than for the previous care system. ${ }^{11}$ The effectiveness, however, remained uncertain, and concern was expressed that this uncontrolled study provided the basis for the introduction of a new leg ulcer service. ${ }^{12}$

A randomised controlled trial was undertaken to compare the effect of four layer bandaging in a clinic setting on healing of venous leg ulcers and health status against the usual home based care provided by district nursing services. The relative cost effectiveness of the two interventions was also evaluated.

\section{Patients and methods}

\section{Recruitment}

The study was approved by appropriate ethics committees. Recruitment was from September 1994 to May 1995 in eight clinics (four urban, two suburban, two semirural) in four community trusts in Trent. The

\author{
School of Health \\ and Related \\ Research \\ (ScHARR), \\ University of \\ Sheffield, Sheffield \\ S1 4DA \\ C Jane Morrell, \\ research fellow \\ Stephen J Walters, \\ statistician \\ Simon Dixon, \\ lecturer \\ Karen A Collins, \\ research associate \\ Jean Peters, \\ research fellow \\ School of Nursing \\ and Midwifery, \\ Samuel Fox House, \\ Northern General \\ Hospital, Sheffield \\ S5 7NA \\ Louise M L \\ Brereton, \\ research associate \\ School of Nursing, \\ University of \\ Manchester, \\ Coupland III \\ Building, \\ Manchester \\ M13 9PL \\ Charles G D \\ Brooker, \\ professor of nursing \\ Correspondence to: \\ Dr Morrell \\ j.morrell1@sheffield. \\ ac.uk
}

BMJ 1998;316:1487-91 


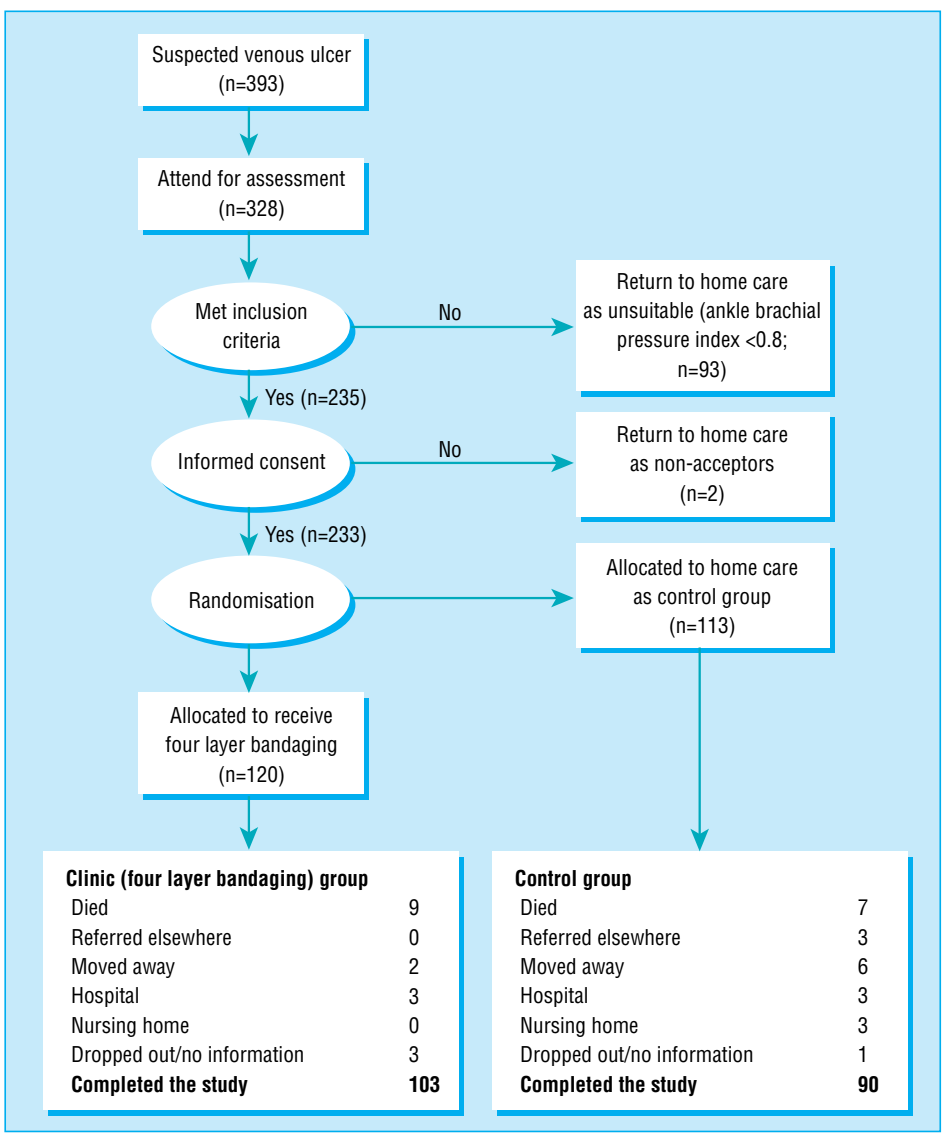

Fig 1 Diagrammatic representation of sample size

inclusion criteria were a venous ulcer below the knee to the foot that was present for at least 3 months and ability to travel to the clinic. Patients were assessed by clinic coordinators using Doppler ultrasound. Those with an ankle brachial pressure index $<0.8$ were excluded. The nurses all adhered to the standardised clinic protocol. A total of 233 patients provided written informed consent (fig 1). A random assignment schedule and serially numbered, sealed, opaque allocation envelopes were prepared in advance for each of the eight clinic sites.

\section{Intervention}

The intervention was weekly treatment in a leg ulcer clinic. Clinic coordinators all completed a course on management of leg ulcers (ENB N18) and additional training days to practice applying four layer bandaging (supervised by experienced practitioners). Treatment adhered as closely as possible to the Charing Cross bandaging technique. ${ }^{9}$ After healing, patients were prescribed class 2 compression stockings and were reviewed by the clinic coordinators every 3 months. For the control group, as it was a pragmatic trial, nurses in the home provided the patients' usual treatment.

\section{Outcomes and follow up}

The primary clinical end point was time to complete healing of all ulcers within the 12 month follow up period. The nurses recorded the date of healing, defined as re-epithelialisation of all ulcers. Secondary end points were health status, time to first recurrence of a healed ulcer, and the number of weeks the patients were free from ulcers.
In the absence of disease specific measures,$^{13}$ four measures of self perceived health status were used to cover all relevant dimensions of health: the 36 item short form health survey (SF-36),${ }^{14}$ the EuroQol (EQ) ${ }^{15}$ the McGill short form pain questionnaire (SF-MPQ), ${ }^{16}$ and the Frenchay activities index. ${ }^{17}$

Questionnaires were posted 12 weeks and 12 months after recruitment to collect data on health status and satisfaction. Reminder questionnaires and telephone calls were used for non-responders or missing responses.

\section{Economic evaluation and analysis}

The economic analysis was undertaken from an NHS perspective. Total estimated NHS costs per patient were calculated by estimating the cost of treatment for leg ulcers (staff time, materials, transport, and overheads) and the cost of use of other health services (general practitioner contacts and hospital). For the control group data were collected for individual home visits to produce a mean cost per home visit. For the clinic group data on use of resources were available for each clinic session but not on an individual basis. The mean cost per attendance per patient was derived from the total cost per session.

Data on the use of health services related to care of leg ulcers were also collected by the postal follow up questionnaires. Data on resources not related to patients-for example, overheads-were collected from service managers. All resources were valued at 1995 prices. Unit costs were taken, when possible, from the local service providers or national data sources. ${ }^{18} 19$ Because of the skewed distributions of the cost data, mean costs per patient for both groups were compared by permutation tests and confidence intervals were calculated by bootstrap methods, ${ }^{20}$ which work by resampling from the observed data and thus make no assumptions on distribution.

\section{Statistical analysis}

Sample sizes were calculated based on the expected difference in rate of healing between the groups after

Table 1 Baseline characteristics of patients recruited. Values are numbers (percentages) of patients unless stated otherwise

\begin{tabular}{lcc} 
Characteristic & $\begin{array}{c}\text { Clinic group } \\
(\mathbf{n = 1 2 0})^{*}\end{array}$ & $\begin{array}{c}\text { Home group } \\
(\mathbf{n = 1 1 3 )} \dagger\end{array}$ \\
\hline Mean (SD) age (years) & $73.8(10.9)$ & $73.2(11.6)$ \\
\hline Mean (SD) area of ulcer $\left(\mathrm{cm}^{2}\right)$ & $16.2(28.9)$ & $16.9(40.8)$ \\
\hline Mean (SD) occurrence of first ulcer (years) & $14.2(14.9)$ & $12.9(15.9)$ \\
\hline $\begin{array}{l}\text { Mean (SD) maximum duration of current ulcer } \\
\text { (months) }\end{array}$ & $27.5(53.8)$ & $29.7(82.3)$ \\
\hline Mean (SD) body mass index (kg/m²) & $27.0(6.7)$ & $27.1(6.0)$ \\
\hline Mean (SD) systolic brachial pressure (mm Hg) & $154.8(28.7)$ & $153.9(24.9)$ \\
\hline Mean (SD) ankle brachial pressure index & $1.08(0.17)$ & $1.10(0.18)$ \\
\hline Women & $77(64)$ & $78(69)$ \\
\hline Married & $56(47)$ & $52(46)$ \\
\hline Living alone & $30(25)$ & $33(29)$ \\
\hline Walking with aid & $66(55)$ & $57(50)$ \\
\hline Family history of leg ulcers & $82(28)$ & $25(22)$ \\
\hline History of deep vein thrombosis & $28(23)$ & $25(22)$ \\
\hline Varicose veins & $77(64)$ & $76(67)$ \\
\hline Rheumatoid arthritis & $14(12)$ & $18(16)$ \\
\hline Heart problems & $13(11)$ & $8(7)$ \\
\hline Osteoarthritis & $47(39)$ & $40(35)$ \\
\hline Diabetes mellitus & $8(7)$ & $10(9)$ \\
\hline
\end{tabular}

*Mean values measured in at least 110 patients. †Mean values measured in at least 100 patients. 
Table 2 Mean (SD) scores on measures of health status at baseline by allocation to treatment in clinic or at home

\begin{tabular}{|c|c|c|}
\hline Measure (range of scores) ${ }^{*}$ & $\begin{array}{c}\text { Clinic group } \\
(n=120) \dagger\end{array}$ & $\begin{array}{l}\text { Control group } \\
(\mathrm{n}=113) \ddagger\end{array}$ \\
\hline \multicolumn{3}{|l|}{ SF-36 (0-100) } \\
\hline Physical function & $41.8(30.0)$ & $45.0(31.5)$ \\
\hline Role limitation—physical & $51.7(42.5)$ & $50.0(40.1)$ \\
\hline Pain & $58.9(28.9)$ & $53.3(28.4)$ \\
\hline General health perception & $66.8(21.5)$ & $62.4(23.1)$ \\
\hline Vitality & $55.7(19.3)$ & $50.8(23.8)$ \\
\hline Social function & $68.2(30.0)$ & $65.2(31.2)$ \\
\hline Role limitation-emotional & $62.5(43.1)$ & $70.5(40.3)$ \\
\hline Mental health & $71.7(20.4)$ & $67.6(22.1)$ \\
\hline \multicolumn{3}{|l|}{ EuroQol } \\
\hline Derived single index $(0-100)$ & $58.1(16.7)$ & $55.4(19.0)$ \\
\hline \multicolumn{3}{|l|}{ Frenchay } \\
\hline Frenchay activities index (15-60) & $36.4(9.9)$ & $36.8(10.4)$ \\
\hline \multicolumn{3}{|l|}{ SF-MPQ } \\
\hline Pain rating index-sensory (0-33) & $8.5(7.2)$ & $9.0(6.7)$ \\
\hline Pain rating index-affective (0-12) & $2.0(3.0)$ & $1.9(2.6)$ \\
\hline No of words chosen (0-15) & $5.4(3.8)$ & $5.6(3.7)$ \\
\hline \multicolumn{3}{|l|}{ Visual analogue scale: } \\
\hline Pain now $(0-10)$ & $3.1(2.8)$ & $3.1(2.9)$ \\
\hline Pain during day $(0-10)$ & $3.8(2.8)$ & $4.1(3.0)$ \\
\hline Pain at night $(0-10)$ & $4.2(3.1)$ & $4.3(3.4)$ \\
\hline
\end{tabular}

*For SF-36, EuroQol, and Frenchay index high score indicates good health; for SF-MPQ high score indicates greater pain.

†For SF-36 general health perception and vitality $n=119$.

łFor SF-MPQ pain rating index (sensory) and No of words chosen $n=112$.

12 weeks. To have an $80 \%$ chance of detecting as significant (at the 5\% level) an increase in healing from $50 \%$ to $70 \%$, 206 patients were required.

All the data analysis was by intention to treat. We used $t$ tests or Mann-Whitney tests for continuous measurements, $\chi^{2}$ tests for categorical data, the Kaplan-Meier method to calculate the time from recruitment for the initial leg ulcer to heal, and the log rank test to compare the healing times of both groups. Previous work suggested that age, ulcer area, ulcer duration, and history of deep vein involvement were important factors in predicting time to healing. ${ }^{21} \mathrm{Cox}$ proportional hazards regression analysis was used to adjust healing times for these variables. ${ }^{22}{ }^{23}$ For each dimension of the four measures of health status, we calculated a summary measure of average health gain per month for all patients as the area under the response curve over the 12 months of follow up, measured with respect to the baseline score. ${ }^{24}$

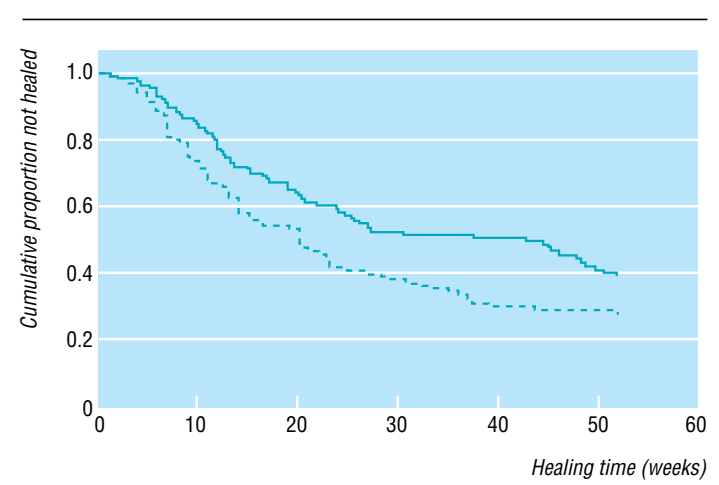

Fig 2 Healing times of initial leg ulcers by treatment group (solid line=control group, $n=113$; dotted line=clinic group; $n=120$ ). Log rank test statistic $4.90 ; \mathrm{df}=1 ; \mathrm{P}=0.03$

\section{Results}

The patients in the two groups were well matched at randomisation with respect to baseline clinical, demographic, and health status measurements (tables 1 and 2). Various treatments were used in the control group (table 3). Access to four layer bandaging for patients in the control group was minimal as all components were not available on prescription. ${ }^{25}$

There was evidence of a difference in the initial healing times for leg ulcers between the groups over the whole follow up (fig 2) with the clinic group tending to heal sooner $(\mathrm{P}=0.03)$. The median healing times were 20 and 43 weeks for patients in the clinic and control groups, respectively. At 12 weeks the KaplanMeier estimates of the cumulative percentages healed at 12 weeks were $34 \%$ in the clinic group and $24 \%$ in the control (difference 10\%, 95\% confidence interval $-2 \%$ to $22 \%)$.

According to the Cox model the initial ulcer was 1.45 times more likely to heal in the clinic group than in the control group (1.04 to 2.03). After adjustment

Table 3 Range of treatments used by district nurses per visit in control group

\begin{tabular}{|c|c|c|}
\hline Treatment & $\begin{array}{l}\text { No of } \\
\text { visits }\end{array}$ & $\begin{array}{l}\text { No (\%) of } \\
\text { times used }\end{array}$ \\
\hline \multicolumn{3}{|l|}{ Wound preparation: } \\
\hline Normal saline & 2114 & $1310(62)$ \\
\hline Water & 381 & $42(11)$ \\
\hline Aqueous solution & 243 & $17(7)$ \\
\hline Nothing & 197 & $12(6)$ \\
\hline Normal saline and other & 163 & $8(5)$ \\
\hline Aqueous solution and other & 155 & $8(5)$ \\
\hline Other combination & 158 & $8(5)$ \\
\hline \multicolumn{3}{|l|}{ Ulcer applications: } \\
\hline Non-adherent dressings & 548 & $88(16)$ \\
\hline Alginate sheets & 487 & $68(14)$ \\
\hline Non-adherent dressings and other & 469 & $66(14)$ \\
\hline Hydrocolloid dressings & 337 & $34(10)$ \\
\hline Hydrogel dressings & 290 & $26(9)$ \\
\hline Paste bandages & 184 & $9(5)$ \\
\hline Nothing & 140 & $6(4)$ \\
\hline Paraffin gauze & 115 & $3(3)$ \\
\hline Alginate sheets and other & 99 & $3(3)$ \\
\hline Hydrocolloid or hydrogel dressings and other & 92 & $3(3)$ \\
\hline Other combinations & 650 & $124(19)$ \\
\hline \multicolumn{3}{|l|}{ Skin applications: } \\
\hline Nothing & 1440 & $605(42)$ \\
\hline Liquid or soft white paraffin & 512 & 77 (15) \\
\hline Steroid cream & 387 & $43(11)$ \\
\hline Aqueous cream & 363 & $40(11)$ \\
\hline Lanolin free emulsifier & 309 & $28(9)$ \\
\hline Other combinations & 399 & $48(12)$ \\
\hline \multicolumn{3}{|l|}{ Securing agents: } \\
\hline Gauze padding & 1007 & $302(30)$ \\
\hline Nothing & 701 & $147(21)$ \\
\hline Simple tape & 544 & $87(16)$ \\
\hline Gauze padding and simple tape & 416 & $50(12)$ \\
\hline Crêpe or crêpe and other & 415 & $50(12)$ \\
\hline Other combinations & 328 & $33(10)$ \\
\hline \multicolumn{3}{|l|}{ Bandages: } \\
\hline Compression & 1445 & $607(42)$ \\
\hline Tubigrip or Tubigrip and other & 599 & $108(18)$ \\
\hline Compression and other & 410 & $49(12)$ \\
\hline Light support or light support and other & 334 & $33(10)$ \\
\hline None & 270 & $22(8)$ \\
\hline Other combinations & 352 & $35(10)$ \\
\hline
\end{tabular}


Table 4 Mean (SD) costs $(£)$ per patient for use of all NHS services by group

\begin{tabular}{|c|c|c|c|}
\hline Service & Clinic group & Home group & $\begin{array}{l}\text { P value for } \\
\text { permutation test }\end{array}$ \\
\hline Leg ulcer treatment/year & 804.03 (535.92) & 681.04 (391.70) & 0.05 \\
\hline GP services/year & $18.33(67.14)$ & $29.82(102.62)$ & 0.31 \\
\hline Hospital services/year & $55.24(319.71)$ & $152.22(680.96)$ & 0.17 \\
\hline Total costs & $877.60(674.30)$ & 863.09 (865.32) & 0.90 \\
\hline $\begin{array}{l}\text { Total costs (with increased overheads for } \\
\text { home visits) }{ }^{\star}\end{array}$ & 877.60 & 913.89 & \\
\hline $\begin{array}{l}\text { Total costs (with other treatments } \\
\text { excluded from home visits costs) } \dagger\end{array}$ & 877.60 & 788.17 & \\
\hline $\begin{array}{l}\text { Total costs (with } 10 \% \text { increase in home } \\
\text { visit costs) } \ddagger\end{array}$ & 877.60 & 931.19 & \\
\hline $\begin{array}{l}\text { Total costs (with } 10 \% \text { reduction in home } \\
\text { visit costs) } \ddagger\end{array}$ & 877.60 & 794.98 & \\
\hline $\begin{array}{l}\text { Total costs (with } 10 \% \text { increase in clinic } \\
\text { attendance costs) } \ddagger\end{array}$ & 958.00 & 863.09 & \\
\hline $\begin{array}{l}\text { Total costs (with } 10 \% \text { reduction in clinic } \\
\text { attendance costs) } \ddagger\end{array}$ & 797.20 & 863.09 & \\
\hline
\end{tabular}

* In baseline analysis no overheads were attributable to home visits as new working practices meant they were expected to be small. Overheads from other work, ${ }^{18}$ believed to be much greater than for nurses in this study, were used to estimate costs.

†Other treatments are sometimes given within home visits. To estimate cost of this work non-treatment time was excluded from home treatment costs.

¥Mean cost estimates for home and clinic visits may be systematically biased because of missing data Possible effects of any bias investigated by adjustment of visit costs by $+/-10 \%$.

for the prognostic variables the initial healing rate of clinic versus control patients was 1.65 (1.15 to 2.35 ).

In the clinic group, $35 \%(27 / 78)$ of patients who initially healed had a recurrence against 23\% (14/62) in the control group. Some patients had several episodes of recurrences and rehealing over follow up. There was no evidence of a difference in the time to first recurrence between the groups (log rank test 0.78 ; $\mathrm{df}=1 ; \mathrm{P}=0.38$ ).

The mean time (in weeks) that each patient was free from ulcers during follow up was 20.1 and 14.2 in the clinic and control groups, respectively. On average, patients in the clinic group had 5.9 more ulcer free weeks (1.2 to 10.5) than control patients.

\section{Health status and satisfaction}

For most dimensions of the SF-36 and EuroQol, health status deteriorated over time, with no difference between the groups. For three dimensions of the SF-MPQ there was evidence that the patients in the clinic group were more likely to experience a reduction in leg ulcer pain per month than control patients. Satisfaction was high in both groups, but there were no significant differences between the groups. ${ }^{26}$

\section{Economic evaluation}

Complete data on resource use were available for $66 \%$ (214/323) of clinics and 62\% (2110/3429) of recorded home visits. From these data, the mean (SD) cost per clinic attendance was estimated at £29.90 (£14.18), while the mean (SD) cost per home visit was estimated at $£ 10.60$ (£3.79).

The annual treatment cost was estimated for each patient by using the mean cost per treatment, the mean frequency of treatment, and patient specific data on weeks with an active ulcer. The mean annual treatment costs were $£ 804.03$ and $£ 681.04$ for the clinic group and the control, respectively; a difference of $£ 122.99$ (£1.56 to £234.84). The control group reported greater use of general practitioner and hospital services (table 4). When these NHS costs were combined with treatment costs, treatment for the clinic group remained £14.51 more expensive (-£201.94 to $£ 214.25)$.

One way sensitivity analysis ${ }^{27}$ was undertaken to investigate the effect that different assumptions might have on mean costs. Changes in assumptions relating to treatment costs and overheads in the control group did not significantly affect the magnitude of costs (see table 4). Weeks free from ulcers was the most appropriate measure available for the cost effectiveness analysis. The additional cost for the clinic group treatment (£14.51) for achieving the benefit of 5.9 ulcer free weeks gave an incremental cost effectiveness ratio of $£ 2.46$ ( $£ 31.94$ to 999.12 ) per ulcer free week.

\section{Discussion}

This subject is of economic importance, given the reported high annual cost to the health service for leg ulcer care. ${ }^{6}{ }^{28}$ Although it was impossible to separate the effect of four layer bandaging or of the specially trained nurses from the clinic setting, the present study pragmatically tested the "package" of care which was already being used elsewhere.

The age distribution of the patients recruited was similar to those reported elsewhere. ${ }^{9102930}$ The baseline distributions of ulcer area and duration of ulcers, however, were much greater than those reported in other studies. ${ }^{10930}$ Within the context of other evidence on four layer bandaging the healing rate in the clinic group (34\%) was lower than the rates reported as $74 \%$ and $69 \%$ in 12 weeks in dedicated clinics. $^{910}$ This probably reflects the larger areas and longer duration of ulcers at baseline in this trial. The nearest comparisons were described in two observational studies as $40 \%$ (of leg ulcers) in 12 weeks $^{31}$ and $42 \%$ (of limbs) of people attending a leg ulcer clinic. ${ }^{32}$ The limitations for use of four layer bandaging in a community clinic include the fact that some people are unable to leave their home and cannot tolerate or do not like the treatment. ${ }^{33}$ Patients have to accept the additional time they must spend travelling and waiting for and having treatment.

The outcomes of the SF-36 and EuroQol seemed to show an overall deterioration in health status in both groups and no improvement in the clinic group associated with the superior healing rate. This could be because the sample size was based on the expected difference in healing rates between the groups and not in health status scores. Other possible explanations are that the measures of health status were not sensitive enough to detect the changes in health specific to the condition or that the time points for follow up did not coincide with the time when the patients improved. The patients did have health problems apart from their leg ulcer and some even died during the trial. Possibly the impact of their leg ulcer was less than the impact of their other health conditions and the tools were accurately describing a deteriorating health status.

\section{Economic evaluation}

We undertook a modelling exercise to make the cost results more applicable to the real world. Clinic coordinators indicated that it was not necessary to use $\mathrm{G}$ or $\mathrm{H}$ grade nurses for the service. Reanalysis of the data with E grade salary costs gave a mean cost per clinic attendance of $£ 27.61$ and an annual NHS cost of around 
Key messages

- Leg ulcer clinics based in the community using four layer compression bandaging can be more clinically effective than usual care provided by the district nursing service

- Community based leg ulcer clinics could be provided more cost effectively than usual home based care for venous leg ulcers

- Recurrence of venous leg ulcers is an important variable that should be measured in future trials of venous leg ulcer care

- It is difficult to measure improvements in health related quality of life among people with venous leg ulcers

$£ 740$ per patient. The restrictions on throughput imposed by the trial produced an artificially high mean cost per attendance at the start and end of the trial. We estimated that by increasing throughput to more than 10 patients the mean cost per attendance could be reduced to $£ 24.87$ and the annual NHS costs to around $£ 670$ per patient. Altering both grade mix and throughput produced a mean cost per attendance of $£ 23.37$ and mean annual NHS costs of around $£ 630$ per patient (compared with $£ 681$ for traditional home treatment). With either scenario, the clinic treatment with four layer bandaging would dominate the home based treatments, being both cheaper and more clinically effective.

The mean cost per clinic attendance (£29.92) was slightly more than the cost reported in Riverside (£22.10 at 1995-6 prices). ${ }^{11}$ The modelling work showed that small changes in the running of the clinics gave a similar cost (£23.37 per attendance). The mean cost per patient per year for clinic group patients in this trial (£804.03) was more than the cost identified in Riverside ( $£ 422$ at $1995-6$ prices). This difference could be explained by the healing rates in the Riverside study ( $80 \%$ of ulcers within 12 weeks).

Although the perspective of the economic evaluation was the NHS, a societal perspective would have included an account of patients' time and personal costs and loss of production due to treatment and poor health. The relative costs may have changed with this perspective as there were greater time costs for the patients in the clinic group.

This trial did not show the impressive healing effects reported in the early studies with four layer bandaging, ${ }^{9}{ }^{10}$ but overall the clinic healing rates improved on care provided by the district nursing service. The improved clinical outcomes were achieved at a small incremental cost to the NHS. If the conditions of nurse grade and throughput per session were optimised, the clinic treatment with four layer bandaging would be more clinically effective and less costly for community trusts than treatment in the home.

We are grateful for the support of the former Trent Regional Health Authority (now NHS Executive Trent). We thank all the participating trusts, clinic coordinators, and the patients who took part in the trial.

Contributors: CJM was involved in the design of the research protocol, coordinated the setting up of the study, and participated in the data collection, management, analysis, and interpretation of the data and the writing of the paper. SJW contributed to the statistical analysis and interpretation of the data and drafting and revising the paper. SD contributed to the economic analysis and interpretation of the data and drafting and revising the paper. $\mathrm{KC}$ and LB participated in preparing databases, data collection, management and analysis, and editing of the paper. JP was involved in setting up the study, preparing databases, data collection, management and analysis, and editing of the paper. CB initiated the formulation of the study hypothesis, secured the funding for the trial, and was involved in the conception and design of the study protocol and the editing of the paper.

Funding: The study was commissioned and funded by the former Trent Regional Health Authority (now NHS Executive Trent).

Conflict of interest: None.

1 Franks PJ, Oldroyd MI, Dickson D, Sharp EJ, Moffatt CJ. Risk factors fo leg ulcer recurrence: a randomised controlled trial of two types of compression stocking. Age Ageing 1995;24:490-4.

2 Hamer C, Cullum NA, Roe BH. Patients' perceptions of chronic leg ulcers.J Wound Care 1994;3:99-101.

3 Anderson MH. Perceived distress in leg ulcer patients. Qual Life Res 1995; $4: 388-9$

4 Hyland ME, Ley A, Thompson B. Quality of life of leg ulcer patients: questionnaire and preliminary findings. J Wound Care 1994;3:294-8.

5 Wilson E. Prevention and treatment of venous leg ulcers. Health Trends 1989;21:97.

6 Laing W. Chronic venous diseases of the leg. London: Office of Health Economics, 1992.

7 Callam MJ, Ruckley CV, Harper DR, Dale JJ. Chronic ulceration of the leg: extent of the problem and provision of care. BMJ 1985;290:1855-6.

8 Cullum N. The nursing management of leg ulcers in the community: a critical review of research. University of Liverpool: HMSO, 1994

9 Blair SD, Wright DDI, Backhouse CM, Riddle E, McCollum CN Sustained compression and healing of chronic venous ulcers. BMJ 1988:297:1159-61.

10 Moffatt CJ, Franks PJ, Oldroyd MI, Bosanquet N, Brown P, Greenhalgh $\mathrm{RM}$, et al. Community clinics for leg ulcers and impact on healing. $B M J$ 1992;305:1389-92

11 Bosanquet N, Franks PJ, Moffatt CJ, Connolly M, Oldroyd MI, Brown P, et al. Community leg ulcer clinics: cost-effectiveness. Health Trends 1993;25:146-8.

12 Fletcher A. Review of classic research: community clinics for leg ulcers. Critique III.J Wound Care 1995;4:471-2.

13 Price P. Defining quality of life. J Wound Care 1993;2:304-6.

14 Ware JE, Sherbourne CD, The MOS 36 item short-form health survey (SF-36). Med Care 1992;30:473-83.

15 EuroOol Study Group. EuroOol-a new facility for the measurement of health-related quality of life. Health Policy 1990;16:199-207.

16 Melzack R. The short form McGill pain questionnaire. Pain 1987:30:191-7.

17 Holbrook M, Skilbeck C. An activities index for use with stroke patients. Age Ageing 1983;12:166-70.

18 Netten A, Dennett J. Unit costs of health and social care. Canterbury: PSSRU, University of Kent, 1996.

19 Office of Health Economics. Compendium of health statistics. London: OHE, 1995.

20 Efron B, Tibishirani RB. An introduction to the bootstrap. New York: Chapman and Hall, 1993.

21 Skene AI, Smith JM, Doré CJ, Charlett A, Lewis JD. Venous leg ulcers: a prognostic index to predict time to healing. BMJ 1992;305:1119-21.

22 Norusis NJ. SPSS for Windows advanced statistics. Release 6.0. Chicago: SPSS, 1993.

23 Collett D. Modelling survival data in medical research. London: Chapman Hall, 1994

24 Matthews JNS, Altman DG, Campell MJ, Royston P. Analysis of serial measurements in medical research. BMJ 1990;300:230-5.

25 Collins K, Morrell J, Peters J, Walters S. Variations in venous leg ulcer care in the community. BrJ Community Nurs 1998;3:6-12.

26 Collins K, Morrell J, Peters J, Walters S, Brooker C. Problems associated with patient satisfaction surveys. Br J Community Health Nurs 1997;2:15663.

27 Briggs A, Sculpher M, Buxton M. Uncertainty in the economic evaluation of health care technologies: the role of sensitivity analysis. Health Econ 1994:3:95-104.

28 Bosanquet N. Cost of venous ulcers: from maintenance therapy to investment programmes. Phlebology 1992;suppl 1:44-66.

29 Blair SD, Backhouse CM, Wright DDI, Riddle E, McCollum C. Do dressings influence the healing of chronic venous ulcers? Phlebolog $1988 ; 31: 129-34$.

30 Colgan MP, Dormandy JA, Jones PW, Schraibman IG, Shanik DG, Young RAL. Oxpentifylline treatment of venous ulcers of the leg. $B M J$ 1990:300:972-5.

31 Thomson B, Hooper P, Powell R, Warin AP. Four-layer bandaging and healing rates of venous leg ulcers. J Wound Care 1996;5:212-6.

32 Simon DA, Freak L, Kinsella A, Walsh J, Lane C, Groarke L, et al Community leg ulcer clinics: a comparative study in two health authorities. $B M J$ 1 1996:312:1648-51.

33 Brereton L, Morrell J, Collins K, Walters S, Peters J, Brooker C. Patients' tolerance of leg ulcer treatments. Br J Community Health Nurs 1997;2: 427-35.

(Accepted 2 February 1998) 